\title{
A influência do capital cultural no gosto e no consumo de música, televisão e cinema
}

\section{The influence of cultural capital on taste and consumption of music, television and movies}

\author{
Teisa Bustamante Maglioni ${ }^{1}$, Gislene Nogueira de Souza ${ }^{2}$, Aline Pereira Sales Morel ${ }^{3}$, \\ Daniel Carvalho de Rezende ${ }^{4}$
}

\begin{abstract}
Resumo
Esse estudo tem como objetivo identificar a influência do capital cultural no gosto e no consumo de TV, música e cinema da população de Lavras-MG. Para tanto, foi realizada uma pesquisa quantitativa descritiva, na qual foram aplicados um total de 400 questionários (para um nível de significância de $95 \%$ e um erro de $5,0 \%$ ). Os métodos de análise utilizados foram a análise de correlação (entre a variável capital cultural do entrevistado com as variáveis intervalares do questionário aplicado) e análises de frequência. Os resultados obtidos evidenciam que o capital cultural exerce influência na diferenciação do gosto nos campos culturais da música, televisão e do cinema. Assume-se, portanto, que a consideração desse fator se faz relevante para o entendimento do consumo cultural nesses campos. Ressalta-se que a realização desse estudo contribuirá para a disseminação do tema consumo cultural e consumo de status no campo das ciências humanas e sociais, haja vista que esse tema ainda é pouco explorado nessas áreas. Além disso, os resultados permitirão a obtenção de resultados adaptados ao contexto brasileiro, uma vez que a maioria dos estudos realizaram essa análise no contexto europeu ou norte americano.
\end{abstract}

Palavras-chaves: Capital cultural. Gosto. Música. Televisão. Cinema.

\begin{abstract}
This study aims to identify the influence of cultural capital in taste and consumption of music, TV and cinema of the population of Lavras-MG. To this end, a descriptive quantitative survey was conducted, in which were applied a total of 400 questionnaires (for a significance level of $95 \%$ and a $5.0 \%$ error). The analytical methods used were correlation analysis (between cultural capital of the interviewee with interval variables of the questionnaire) and frequency analysis. The results show that the cultural capital influences the differences in taste on the fields of music, television and cinema. It is assumed, therefore, that the consideration of this factor is relevant to the understanding of cultural consumption in these fields. It is emphasized that the realization of this study will contribute to the spread of cultural consumption and status consumption in the field of humanities and social sciences, given that this topic is still little explored in these areas. Moreover, the results enable to obtain results adapted to Brazilian context, since most studies performed this analysis in the European or North American context.
\end{abstract}

keywords: Cultural capital. Taste. Music. Television. Cinema.

${ }^{1}$ Graduanda em Administração na Universidade Federal de Lavras (UFLA). Bolsista PIBIC/CNPq. E-mail: teisacfn@administracao. ufla.br

${ }^{2}$ Graduanda em Administração na Universidade Federal de Lavras (UFLA). Bolsista PIBIC/CNPq. E-mail: gislenensouza@ hotmail.com

${ }^{3}$ Doutoranda em Administração, Pesquisadora do Grupo de Estudos em Marketing e Comportamento do Consumidor. E-mail: alinepereirasales@gmail.com

${ }^{4}$ Doutor em Ciências Sociais em Desenvolvimento, Agricultura e Sociedade Adjunto da Universidade Federal de Lavras. PósDoutorado na Lancaster University. Professor adjunto da Universidade Federal de Lavras. 


\section{Introdução}

O entendimento da mecânica e das consequências sociais do consumo utilizado para expressar a posição social (comumente denominado de consumo de status ou consumo de estilo de vida) tem sido o centro de um rico debate teórico (BOURDIEU, 1984; LAMONT, 1992; SIMMEL, 1904; VEBLEN, 1980).

A mais reconhecida teoria relativa ao consumo de status foi elaborada por Bourdieu (1984). Porém, embora a teoria de consumo e distinção social de Bourdieu e seus desdobramentos tenha inegavelmente se tornado referência para os estudos nessa área, várias limitações têm sido apontadas em estudos recentes. Um dos problemas consiste no fato de que sua base empírica reside quase que exclusivamente em países da Europa ou nos EUA, e que sua pretensa universalidade ainda não foi apropriadamente testada em outras regiões do mundo, especialmente nos países em desenvolvimento.

Ao contrário do modelo de consumo de status europeu, baseado fundamentalmente na obra de Bourdieu (1984), as classes privilegiadas nos países em desenvolvimento não parecem tão autônomas e não definem seu gosto prioritariamente por influências internas. Estudos demonstram a enorme influência dos produtos e do estilo de vida americano e europeu sobre as classes médias desses países (USTUNER; HOLT, 2009).

Além disso, a estrutura social brasileira indica particularidades importantes que devem ser exploradas na criação de um modelo de consumo de status, com destaque para o notório desequilíbrio de classe, além de uma estrutura de valorização ocupacional distinta e uma relação entre ocupação e renda mais aguda do que nos países mais desenvolvidos. Nesse sentido, a desigualdade de classes apresenta-se de forma marcante na sociedade brasileira e suas consequências sobre as estratégias de elaboração do gosto e do consumo de status devem ser mais bem compreendidas.

Entre as áreas de consumo (mais comumente denominadas de campos) estudadas por Bourdieu (1984) destacam-se os chamados campos culturais. Entre os campos culturais mais estudados destacam-se a literatura, a pintura, o cinema, a televisão e a música. Optou-se nesse estudo pelos 3 últimos campos acima citados tendo em vista a sua relevância econômica e cultural nos dias atuais. Além disso, nesses 3 campos as mudanças nos padrões de gosto e consumo têm sido marcantes nos últimos anos devido ao crescimento da internet, aos massivos investimentos na produção cinematográfica nacional e à queda marcante nas audiências da televisão aberta em detrimento da TV paga.

Assim, tem-se como objetivo geral do artigo: identificar a influência do capital cultural no gosto e no consumo de TV, música e cinema da população de Lavras-MG. Ressalta-se que a realização desse estudo contribuirá para a disseminação do tema consumo cultural e consumo de status no campo das ciências humanas e sociais, haja vista que esse tema ainda é pouco explorado nessas áreas. Além disso, os resultados permitirão a obtenção de resultados adaptados ao contexto brasileiro, uma vez que a maioria dos estudos realizaram essa análise no contexto europeu ou norte americano.

\section{Consumo de Status, Gosto e Capital Cultural}

Uma das correntes teóricas mais expressivas no que se refere ao consumo de status $^{5}$ advém dos estudos do sociólogo francês Pierre Bourdieu. Segundo Bourdieu (1984), os julgamentos de gostos e de preferências não são o reflexo da estrutura social, mas um meio de afirmar ou de conformar uma vinculação social. Existem três construtos básicos na teoria de Bourdieu: capital cultural, habitus e

\footnotetext{
${ }^{5}$ Outra corrente de estudos que se destaca é a defensora da teoria de Veblen (1980) e Simmel (1904), que cunharam o termo trickledown consumption. O foco desses autores reside no fato de que os símbolos de status da classe alta se tornavam também objeto de desejo de classes mais baixas, que objetivavam ascender socialmente.
} 
campo social. Esses três elementos se relacionam e constituem o âmago da teoria de consumo de status por ele desenvolvida.

Para Bourdieu (1984), a vida social pode ser concebida como um jogo multidimensional de status em que as pessoas fazem uso de três tipos de recursos (capital econômico, social e cultural). O capital cultural, principal foco da análise, consiste de um conjunto de gostos, habilidades, conhecimentos e práticas distintivos e raros, que existe em três formatos básicos: corporificado, objetificado e institucionalizado. O capital cultural corporificado se manifesta no comportamento, forma de se vestir, falar, etc. O capital cultural objetificado se refere a posses e, por implicação, aos julgamentos de gosto envolvidos na sua aquisição. Já o capital cultural institucionalizado confere honra derivada primariamente das qualificações educacionais relacionadas ao diploma e à reputação da instituição de ensino.

O conceito de capital cultural elaborado por Bourdieu foca no processo sistemático pelo qual indivíduos escolarizados nas formas legítimas de cultura possuem vantagens sobre classes populares e trabalhadores que não têm acesso a essas formas legítimas de cultura. O capital cultural é acumulado e reproduzido, segundo Bourdieu, fundamentalmente pelo sistema educacional. Famílias com alto nível educacional, interagindo com outras famílias de mesmo nível social, que estudam em colégios e universidades de prestígio, em áreas que enfatizam pensamento abstrato e crítico e o papel do simbólico, fazem com que as elites culturais sejam subjetivamente incorporadas de modos de pensar, sentir e agir simbolicamente distintivos, processo denominado por Bourdieu de habitus. Da mesma maneira, indivíduos de classes trabalhadoras, estudando em colégios de menor prestígio e convivendo com famílias de mesmo nível, irão adquirir gostos distintos e característicos de um nível de capital cultural mais baixo (BOURDIEU, 1984; HOLT, 1998).

\section{Consumo e Distinção nos Campos Culturais do Cinema, Televisão e Música}

O cinema tem importância de âmbito econômico, cultural e simbólico (HAMBURGER, 2007). Conforme observado por Morettin (2011, p. 185), "alguns países recorreram ao cinema para apresentar aspectos das suas atividades econômicas e culturais". Assim, o cinema pode ser visto como um meio para a divulgação de valores culturais, além de um instrumento consolidado de comunicação de massa.

Nas pesquisas realizadas por Austin e Gordon (1987) e por Jowett (1985 apud FU, 2013), os cinéfilos indicaram que o gênero é a maior razão para assistir a um filme específico. Já Fleck e Casagrande (2006) buscaram compreender a motivação das pessoas para frequentar o cinema e descobriram que o principal motivo não é causado por razões culturais, mas sim pela busca por entretenimento.

Fu (2013), por sua vez, realizou uma pesquisa comparando o gosto por gêneros de filmes nos EUA e em outros países. O autor concluiu que o público com culturas similares aos dos Estados Unidos não só assistem a filmes de Hollywood, como também exibem gostos pelos gêneros que são semelhantes aos norte-americanos. O autor utiliza do conceito de proximidade-cultural para explicar esse efeito, segundo o qual o público tende a preferir e escolher as mídias produzidas por culturas mais perto de seu próprio país. Isto porque as pessoas podem assimilar e refletir melhor sobre conteúdo, que emana de valores, costumes e atitudes semelhantes ou familiares.

Em relação à televisão, pode-se dizer que ela exerce influência na formação da identidade cultural e capacidade comunicativa (BAUER, 2002). Como aponta Gambaro (2012), o consumo cultural através da televisão tem um duplo significado: o conteúdo assistido pelo telespectador (novela, telejornal, etc.) e o meio que utiliza para receber o conteúdo (via cabo, antena, etc.). Caparelli (1982 apud MATTOS, 
1990) acrescenta que, além de divertir e instruir, a televisão também funciona como veículo de valorização dos bens de consumo, por meio das propagandas, e como instrumento de manutenção da ideologia da classe dominante. A esse respeito, Melo (1977) destaca o controle da elite política e econômica exercido sobre a televisão e os demais veículos de massa.

Em seu estudo, Bennett et al. (2009) descobriu que assistir televisão e ir ao cinema estão entre as atividades culturais mais amplamente praticadas e partilhadas. Esses autores evidenciaram que tanto a TV como o cinema mostram divisões mais significantes em relação à classe, sendo essa relação positiva no caso da ida ao cinema (apresentando forte relação com a classe profissional executiva) e negativa no caso de assistir televisão (no caso, a televisão acaba por ocupar uma posição de ativo negativo no processo de formação do capital cultural).

No que tange o consumo cultural da música, observa-se que diversos estudiosos têm se debruçado sobre o tema. No estudo realizado por Bennett et al. (2009), esse campo se revelou como o mais dividido e controverso entre todos os campos culturais pesquisados, assim como o mais popular. Segundo esses autores, a música serve, inclusive, como pano de fundo para outras as práticas, como assistir televisão e ver filmes.

Autores como Savage e Gayo (2011), Bennett et al. (2009), Tampubolon (2008), Chan e Goldthorpe (2006), entre outros, identificaram em seus estudos posições de dominância e de subordinação no campo da música, relacionadas a diferentes níveis de experiência e conhecimento.

Nesse sentido, Bennett et al. (2009) ressaltam que a familiaridade com a música clássica ainda se revela como uma forma de capital cultural institucionalizado e que a participação em eventos relacionados a esse gênero musical são como uma forma de capital cultural objetivado, ambos podendo se converter em capital social.
Tampubolon (2008) e Chan e Goldthorpe (2006) chamam a atenção para o fato de classe dominante claramente se distinguir da classe dominada (popular) pela sua vasta gama de consumo musical, incluindo os gêneros que também são ouvidos pela classe popular. A classe dominada, por sua vez, se caracteriza por um consumo cultural altamente estruturado.

Rimmer (2011), por sua vez, esboça o conceito de habitus musical. Destaca o autor que, assim como a socialização primária e a secundária exercem influência direta sobre o desenvolvimento do habitus, da mesma forma pode ser com as dimensões musicais, ou seja, a socialização musical primária e secundária também deverá desempenhar um papel fundamental no desenvolvimento de habitus musical dos atores. Nesse sentido, são envolvidas questões sobre o papel de uma ampla gama de atores (como os colegas, irmãos e outros membros da família, e a mídia) e de fatores (como o acesso e a exposição dos atores a diferentes materiais e experiências musicais e a própria educação). Esse autor então argumenta que, embora o conceito de campo proposto por Bourdieu seja aplicável à música e às suas atividades correlatas, tal campo teria de ser conceitualmente desagregado e percebido como composto por inúmeros subcampos, uma vez que diferentes espécies de capital operaram no campo musical.

Por fim, deve-se considerar que, desde que o estudo de Bourdieu (1984) foi realizado, a difusão da mídia tem gerado uma ampla gama de gostos e práticas culturais. Por exemplo, enquanto a televisão aberta ganhava espaço como um fenômeno cultural quando da realização do estudo de Bourdieu, atualmente, a emergência dos satélites e TVs a cabo tem enfraquecido a sua posição. Além disso, o crescimento vertiginoso no uso de computadores e o advento da Internet também têm implicado em um contexto cultural mais complexo e amplo no campo do cinema. Ademais, com o advento das gravações musicais, a música passou a exercer um papel ainda mais central em grande parte das subculturas populares, em especial, em grupos desfavorecidos, grupos jovens e em minorias étnicas. A digitalização 
das formas musicais também proporcionou a ampliação das possibilidades de mobilização entre diferentes dispositivos para gravação, armazenamento e reprodução da música. Esse fenômeno também tornou possível a customização das playlists pelos próprios usuários, algo inimaginável até então (BENNETT et al., 2009). A massificação de aparelhos eletrônicos como MP3, MP4 e smartphones, além do acesso facilitado à internet, também têm mudado drasticamente as formas de consumir música.

Todo esse movimento sugere a necessidade de análises mais refinadas a respeito. Esse refinamento inclui a distinção entre as posições desses campos nesse processo, haja vista que, embora existam evidentes pontos de similaridade, eles também se distinguem em muitos aspectos (BENNETT et al., 2009). O presente estudo representa um esforço inicial de investigação no contexto brasileiro.

\section{Procedimentos Metodológicos}

Utilizando a classificação proposta por Gil (2002), essa pesquisa pode ser classificada como quantitativa descritiva. A técnica utilizada para a coleta de dados foi a aplicação de questionários semiestruturados. A elaboração do instrumento para coleta de dados foi fundamentada no questionário elaborado por Bennett et al. (2009). Assim como definido por esses autores, o questionário abarcou questões relacionadas tanto ao gosto quanto à participação (consumo efetivo).

Um pré-teste foi realizado para que, antes da realização definitiva do estudo, fossem identificadas inconsistências que pudessem distorcer a compreensão dos respondentes em relação às assertivas. $\mathrm{O}$ pré-teste foi conduzido com 18 pessoas, seguindo a orientação de Gil (2002) de que o pré-teste deve ser feito com 10 a 20 pessoas. A partir do pré-teste, as questões foram reposicionadas no questionário e algumas questões foram excluídas. Assim, o questionário final contemplou 36 questões, sendo 9 destinadas ao campo da música, 8 destinadas ao campo do cinema, 10 destinadas ao campo da televisão e 9 relacionadas a dados sociodemográficos dos respondentes.
O universo de estudo desta pesquisa abrange toda população de Lavras, cidade pertencente à mesorregião do Campo das Vertentes, no estado de Minas Gerais. Sua população urbana foi estimada pelo Censo de 2010 em 92.171 habitantes. A escolha dessa cidade justifica-se por motivo de conveniência, além da alta expressividade atingida pelas cidades de porte médio no cenário atual, as quais têm apresentado maior crescimento populacional anual (BORLINA FILHO, 2012), o que reforça a importância de se compreender o comportamento dos habitantes desses locais. A definição da amostra foi aferida para um nível de significância de 95\% e um erro de 5,0\%. A amostragem foi feita por conveniência e a abordagem dos entrevistados para coleta dos dados foi feita nas ruas, em diferentes pontos da cidade.

Dessa forma, foram aplicados um total de 400 questionários durante o mês de junho de 2015. Os dados obtidos foram tabulados e analisados com o auxílio do software aplicativo Statistical Package for the Social Sciences (SPSS). Os métodos de análise utilizados foram a análise de correlação (entre a variável capital cultural do entrevistado com as variáveis intervalares do questionário aplicado) e análises de frequência. A metodologia utilizada para o cálculo do capital cultural encontra-se descrita a seguir.

\section{Cálculo do capital cultural}

A definição do nível de Capital Cultural (CC) dos entrevistados foi realizada com base no trabalho de Holt (1998). Nesse sentido, foram avaliados e atribuídos escores à escolaridade e ocupação do entrevistado e também à escolaridade e ocupação do seu pai. Além disso, como uma adaptação do trabalho supramencionado, foi considerada a escolaridade e ocupação da mãe do entrevistado no cálculo do CC, considerando a crescente participação da mulher no mercado de trabalho e seu poder nas decisões de compra familiares.

Apresenta-se no Quadro 1 os escores referente à escolaridade e no Quadro 2 os escores relativos à ocupação. 
Quadro 1 - Escores referentes à escolaridade

\begin{tabular}{|c|c|}
\hline Escolaridade & Pontuação \\
\hline Não alfabetizado & 1 \\
\hline Ensino Fundamental & 2 \\
\hline Ensino Médio & 3 \\
\hline Ensino Técnico & 4 \\
\hline Ensino Superior & 5 \\
\hline Pós Graduação & 6 \\
\hline
\end{tabular}

Fonte: Elaborado pelos autores, adaptado de Holt (1998).

Quadro 2 - Escores referentes à ocupação

\begin{tabular}{|c|c|}
\hline Ocupação & Pontuação \\
\hline $\begin{array}{l}\text { Serviço manual } \\
\text { (Ajudante de Pedreiro, Armador de Ferragem, Auxiliar de Limpeza, Desempregado/ } \\
\text { Pensionista/ Nenhum, Lavadeira, Pedreiro, Sacoleira) }\end{array}$ & 1 \\
\hline $\begin{array}{l}\text { Serviço de Apoio/Administrativo básico } \\
\text { (Açougueiro, Agente de Estação, Atendente, Auxiliar de serviços gerais, Bombeiro } \\
\text { Hidráulico, Caminhoneiro, Chefe de Estação, Chefe de trem, Costureira, Cozinheiro, } \\
\text { Despachante, Eletricista, Frentista, Garçom, Guarda, Lanterneiro, Manicure, Maquinista, } \\
\text { Marceneiro, Mecânico, Mestre de Obras, Metalúrgico, Montador, Motorista, Operador } \\
\text { de Máquinas, Operário, Padeiro, Porteiro, Produtor Rural, Serralheiro, Serviço Escolar, } \\
\text { Soldador, Torrefador, Tratorista, Vigia, Vigilante, Zelador) }\end{array}$ & 2 \\
\hline $\begin{array}{l}\text { Vendas, técnico básico, gerencial básico, pequeno empresário } \\
\text { (Agente de Saúde, Analista de Sistema, Assistente Social, Autônomo, Auxiliar } \\
\text { Administrativo, Auxiliar de Dentista, Auxiliar de Enfermagem, Balconista, Bombeiro, } \\
\text { Cabeleireira, Civil, Comerciante, Compradora de materiais, Construtor, Contador, } \\
\text { Corretor de Imóveis, Editor de Imagem, Empresário, Esteticista, Farmacêutico, Faturista, } \\
\text { Ferroviário, Fiscal, Funcionário Público, Jogador de Futebol, Oficial de Justiça, Operador } \\
\text { de Estação de tratamento de água, Orçamentista, Projetista, Rádio técnico, Representante } \\
\text { Comercial, Secretário, Supervisor, Taxista, Técnico Agrícola, Técnico contábil, Técnico } \\
\text { da Informação, Técnico de Irrigação, Técnico de Redes, Técnico de Som, Técnico do } \\
\text { Seguro Social, Técnico Eletrônico, Técnico em Informática, Técnico em segurança do } \\
\text { trabalho, Ténico em Eletrônica, Tipógrafo, Vendedor) }\end{array}$ & 3 \\
\hline $\begin{array}{l}\text { Alto nível técnico ou gerencial, cultura de nível básico } \\
\text { (Administrador, Artesã, Bancário, Biólogo, Biomédico, Bioquímico, Consultor, Design } \\
\text { de interiores, Diretor de escola, Enfermeira, Fisioterapeuta, Fotógrafo, Industrial, } \\
\text { Industriário, Militar, Pedagoga, Professor da Educação Básica e Média, Publicitário, } \\
\text { Químico, Relações Públicas, Topógrafo, Zootecnista) }\end{array}$ & 4 \\
\hline $\begin{array}{l}\text { Produtores culturais, profissional liberal especializado } \\
\text { (Advogado, Dentista, Engenheiro, Estudante Pós-Graduação, Professor do Ensino } \\
\text { Superior, Médico, Médico Veterinário, Músico, Pesquisador, Psicólogo) }\end{array}$ & 5 \\
\hline
\end{tabular}

Fonte: Elaborado pelos autores, adaptado de Holt (1998). 
Outras adaptações utilizadas nesse estudo para aproximar o cálculo do CC da realidade estudada foram:

a) Foi atribuída a mesma pontuação (5) para estudante de "pós-graduação" e "pesquisador";

b) Para os respondentes que especificaram sua profissão como "professor do ensino superior" ou "professor da educação básica" foram atribuídas, respectivamente, as pontuações 5 e 4. Para os que não especificaram o nível do ensino, foi atribuída a pontuação média das duas ocupações citadas anteriormente $(4,5)$;

c) Para o cálculo do capital cultural dos respondentes que se identificaram como estudantes do ensino fundamental, médio, técnico e superior, considerou-se a média da pontuação das profissões dos pais. No caso de ausência de resposta na profissão do pai ou da mãe do respondente, foi considerado apenas pontuação da profissão disponível. Se houvesse ausência de resposta nas profissões de ambos (pai e mãe), o respondente deveria ser excluído da amostra;

d) Para o cálculo do capital cultural da ocupação das mulheres descritas como "do lar", sua pontuação foi a média da pontuação de todas as mulheres que trabalham, inclusive das mães dos respondentes;

e) As respostas em branco ou as respostas dadas como "Nenhum" e "aposentado", na profissão do pai ou da mãe do entrevistado foram consideradas como dados ausentes (missing).

Para medir o Capital Cultural foi utilizada a seguinte fórmula:

$$
C C=\left(\frac{O P+E P}{2}\right)+\left(\frac{O M+E M}{2}\right)+O E+E E
$$

Ou seja, ocupação do pai (OP) somada a escolaridade do pai (EP) divido por dois, mais a ocupação da mãe (OM) somada a escolaridade da mãe (EM) dividido por dois, mais a ocupação do entrevistado (OE) somada a escolaridade do entrevistado (EE). Os índices de Capital Cultural dos entrevistados variam entre o escore mínimo de 5 e máximo de 27. Os níveis de Capital Cultural ficaram, então, definidos na forma apresentada no Quadro 3.

Quadro 3 - Níveis de Capital Cultural

\begin{tabular}{|c|c|}
\hline Nível de Capital Cultural & Intervalo \\
\hline Baixo Capital Cultural & $5-13$ \\
\hline Médio Capital Cultural & $14-18$ \\
\hline Alto Capital Cultural & $19-27$ \\
\hline
\end{tabular}

Fonte: Elaborado pelos autores.

Os resultados obtidos a partir desses procedimentos serão apresentados e discutidos na seção a seguir.

\section{Resultados e Discussão}

A seguir serão discutidos os resultados obtidos através do presente estudo. Conforme se observa na Tabela 1, o perfil dos respondentes é composto, em sua maioria, por indivíduos do sexo feminino, com idade entre 21 e 40 anos, ensino médio completo e renda familiar mensal de 4 a 10 salários mínimos. Com relação ao capital cultural, a maioria dos entrevistados foi classificada como médio capital cultural.

Tabela 1 - Caracterização sociodemográfica dos entrevistados

\begin{tabular}{ll}
\hline Sexo & $52,0 \%$ feminino \\
& $48,0 \%$ masculino \\
\hline \multirow{3}{*}{ Idade } & $25 \%$ de 15 a 20 anos \\
& $39,8 \%$ de 21 a 40 anos \\
& $24,5 \%$ de 41 a 60 anos \\
& $10,8 \%$ acima de 60 anos \\
\hline & $0,3 \%$ não alfabetizado \\
& $12,5 \%$ tem ensino fundamental \\
Escolaridade & $44,8 \%$ tem ensino médio \\
& $7,5 \%$ tem ensino técnico \\
& $22,5 \%$ tem ensino superior \\
& $12,5 \%$ tem pós-graduação
\end{tabular}

continua... 
continuação

17,0\% até 2 salários mínimos

$28,1 \%$ de 2 a 4 salários mínimos

Renda $\quad 31,4 \%$ de 4 a 10 salários mínimos $15,9 \%$ de 10 a 20 salários mínimos

7,6\% acima de 20 salários mínimos

$\begin{array}{ll}\text { Capital } & 31,4 \% \text { alto capital cultural } \\ \text { Cultural } & 43,3 \% \text { médio capital cultural } \\ & 25,3 \% \text { baixo capital cultural }\end{array}$

Fonte: Dados da pesquisa.
Os respondentes também foram questionados acerca de quais e quantos aparelhos eletrônicos possuem em casa e sobre os aparelhos de uso pessoal que possuem. Conforme se observa na Tabela 2, a maioria dos respondentes possui um aparelho de DVD/ Blu-Ray em casa (51,7\%); não possui Hometheater $(69,9 \%)$; possui pelo menos uma TV plasma, LED ou LCD $(39,9 \%)$ e um computador pessoal/notebook (40,7\%). Quanto aos aparelhos de uso pessoal, a maioria possui um smartphone (64, $8 \%$ ) e não possui Tablet $(66,8 \%)$.

Tabela 2 - Posse de aparelhos eletrônicos

\begin{tabular}{ccccccc}
\hline & Não possui & Possui 1 & Possui 2 & Possui 3 & Possui 4 & Possui 5 ou 6 \\
\hline DVD/Blu-Ray & $29,6 \%$ & $51,7 \%$ & $15,7 \%$ & $2,6 \%$ & $0,5 \%$ & - \\
\hline Hometheater & $69,9 \%$ & $28,5 \%$ & $1,3 \%$ & $0,3 \%$ & - & - \\
\hline $\begin{array}{c}\text { TV de plasma, LED ou } \\
\text { LCD }\end{array}$ & $14,2 \%$ & $39,3 \%$ & $27,4 \%$ & $9,4 \%$ & $6,3 \%$ & $3,3 \%$ \\
\hline $\begin{array}{c}\text { Computador pessoal/ } \\
\text { Notebook }\end{array}$ & $14,6 \%$ & $40,7 \%$ & $22,5 \%$ & $13,9 \%$ & $5,1 \%$ & $3,3 \%$ \\
\hline Smartphone & $24,4 \%$ & $64,8 \%$ & $5,3 \%$ & $2,9 \%$ & $1,5 \%$ & - \\
\hline Tablet & $66,8 \%$ & $29,2 \%$ & $3,4 \%$ & $0,5 \%$ & - & - \\
\hline
\end{tabular}

Fonte: Dados da pesquisa.

Por meio dos resultados apresentados na Tabela 2 também é possível notar que, em muitas casas, há mais de um aparelho de televisão e DVD, que deixaram de ser aparelhos de uso coletivo e passaram a ser de uso pessoal; em algumas casas, cada membro da família possui uma televisão em seu quarto.

Vale ressaltar que o acesso aos aparelhos tecnológicos cresceu ao longo dos últimos anos no Brasil. Pode-se dizer que um dos fatores que contribuíram com esse incremento no consumo desses aparelhos foi a facilitação do financiamento, proposto pelo governo federal em
2013. Como exemplo, pode-se citar o Programa "Minha casa melhor", que destinava uma linha de crédito especial para a compra de móveis, eletrodomésticos e eletrônicos aos beneficiários do programa "Minha Casa, Minha Vida" (PORTAL BRASIL, 2013; WALTRICK, 2014).

Ao analisar a influência do capital cultural sobre a posse desses aparelhos (Tabela 1), verificou-se que os indivíduos com capital cultural mais elevado tendem a ter mais aparelhos como computador pessoal/ notebook, TV de plasma, LED ou LCD, smartphone, hometheater, tablet e aparelhos de DVD/Blu-Ray. Esse 
resultado pode ser associado à renda dessas pessoas, que por ser mais elevada, o que facilitaria a compra de uma quantidade maior desses itens. Esse resultado é corroborado pela pesquisa de Orçamentos Familiares (IBGE, 2010), segundo a qual quanto maior a renda familiar, maiores os gastos com esse tipo de aparelho.
Analisando a variável nominal capital cultural com as variáveis intervalares do questionário aplicado, no que diz respeito ao gosto e ao consumo de TV, música e cinema, também foi possível observar correlações significativas. Apresentam-se na Tabela 3 os resultados obtidos.

Tabela 3 - Correlações significativas entre capital cultural e consumo de TV, música e cinema

\begin{tabular}{|c|c|c|}
\hline & Variáveis intervalares & Correlação com capital cultural \\
\hline \multirow{4}{*}{ Televisão } & Possui TV de plasma, LED ou LCD & $0,290 * *$ \\
\hline & Possui TV por assinatura ou cabo & $-0,167 * *$ \\
\hline & Horas que assiste TV durante a semana & $-0,154 * *$ \\
\hline & Horas que assiste TV durante os fins de semana & $-0,118 *$ \\
\hline \multirow{8}{*}{ Música } & Gostar de MPB & $0,320 * *$ \\
\hline & Gostar de pop & $0,170 * *$ \\
\hline & Gostar de rock & $0,169 * *$ \\
\hline & Gostar de música clássica & $0,123 *$ \\
\hline & Gostar de heavy metal & $-0,137 * *$ \\
\hline & Gostar de sertanejo & $-0,138 * *$ \\
\hline & Gostar de gospel & $-0,232 * *$ \\
\hline & Frequência com que vai a shows e eventos musicais & $-0,202 * *$ \\
\hline \multirow{3}{*}{ Cinema } & Possui Aparelhos de DVD/Blu-Ray & $0,129 *$ \\
\hline & Possui Hometheater & $0,210 * *$ \\
\hline & Frequência com que vai ao cinema & $-0,329 * *$ \\
\hline \multirow{3}{*}{ Outros } & Possui smartphone & $0,237 * *$ \\
\hline & Possui tablet & $0,153 * *$ \\
\hline & Possui computador pessoal/notebook & $0,315 * *$ \\
\hline
\end{tabular}

**Correlação é significante no nível de 0,001.

*Correlação é significante no nível de 0,005 .

Fonte: Dados da pesquisa.

Conforme se observa na Tabela 3 , em relação ao consumo de televisão, as pessoas com menor capital cultural têm maior probabilidade de passar mais tempo assistindo TV, tanto durante a semana como nos fins de semana. De forma semelhante, no estudo desenvolvido na Inglaterra por Bennett et al. (2009) a televisão também se mostrou como uma atividade de lazer importante para as 
classes mais baixas (consequentemente, de menor capital cultural). Segundo os autores, o aspecto possivelmente mais distintivo das práticas de profissionais executivos é o baixo nível de consumo de televisão em relação às outras duas classes $(24 \%$ da classe profissional executiva assiste menos de uma hora nos dias da semana, comparado com $10 \%$ da classe trabalhadora; enquanto apenas 19\% da classe profissional executiva assiste cinco horas ou mais nos finais de semana, comparado com 30\% da classe média e $43 \%$ da classe trabalhadora). Nesse estudo, os indivíduos menos escolarizados (consequentemente, de menor capital cultural) também tendiam a passar mais tempo assistindo TV: indivíduos com educação universitária se mostraram três vezes mais propensos a assistir com moderação (58\%) do que aqueles sem qualificações educacionais (21\%). Uma pesquisa feita pelo Ibope (ASSOCIAÇÃO BRASILEIRA DE TV POR ASSINATURA, 2014), também observou que os indivíduos pertencentes às classes DE passam maior tempo assistindo TV do que as outras classes. Dessa forma, é possível que esses indivíduos utilizem mais a televisão como fonte de lazer e aproveitem uma parte do seu final de semana para assistir os seus canais preferidos.

A televisão aberta brasileira é, atualmente, formada por grandes redes nacionais (Rede Globo, Bandeirantes, Record, Rede TV, SBT) com suas afiliadas regionais e tem levado entretenimento e informação aos expectadores. Neste contexto, buscaram-se analisar quais são as emissoras mais assistidas pelos respondentes. Os resultados obtidos revelam que a emissora de TV aberta mais assistida é a Rede Globo (55\%), seguida pela Record (8,4\%). As demais emissoras representaram 12,4\% da amostra e os outros $24,3 \%$ declararam que não assistem TV aberta.

Embora majoritariamente citada pelos respondentes, a Rede Globo vem perdendo audiência ao longo do tempo de acordo com os índices de ibope das emissoras. Em abril de 2014 a emissora perdeu $8 \%$ de ibope das 7 h à 0 h em São Paulo; a
Record cresceu $27 \%$, o SBT cresceu $20 \%$, a Band cresceu 30\% e a RedeTV! subiu 23\% (FELTRIN, 2014). Em 2015, segundo o Portal Metrópole (2015), em janeiro a emissora Globo marcava 13,3 pontos de média, seguida da Record (5,5 pontos de média), SBT $(5,4$ pontos de média), Band $(2,1$ pontos de média) e RedeTV! ( 0,8 pontos de média).

Vale ressaltar que o significativo percentual de respondentes que declaram não assistir TV aberta se deve, em grande medida, à disseminação das TVs por assinatura (TVA), do Serviço de Distribuição Multiponto Multicanal (MMDS ou Cabo Wireless), da Televisão Digital via Satélite (DTH) e da Televisão por cabo. Segundo a Associação Brasileira de Televisão por Assinatura (ASSOCIAÇÃO BRASILEIRA DE TV POR ASSINATURA, 2015), o setor de TV por assinatura cresceu nos últimos anos, passando de 12,7 milhões de assinantes em 2011 para 21,2 milhões em 2014. $\mathrm{O}$ principal diferencial da TV paga em relação à TV aberta é a variedade de programas, com destaque para eventos esportivos, obras não seriada de ficção, documentários e animações (ANCINE, 2010).

$\mathrm{Na}$ presente pesquisa, 59,4\% dos entrevistados possuem TV por assinatura ou a cabo. Quando analisada a influência do capital cultural sobre essa variável, foi possível observar uma correlação negativa, ou seja, quanto menor o capital cultural, maior a probabilidade de possuir TV por assinatura ou cabo. Esse resultado encontra respaldo no estudo feito pelo Instituto Data Popular (2013) sobre os hábitos dos usuários de TV por assinatura. De acordo com os resultados desse estudo, 29\% dos assinantes de serviço de TV por assinatura são "entrantes" e a cada 100 novos clientes de TV por assinatura, 95 pertencem às classes C e D. Juntos, as classes $\mathrm{C}$ e D representam $66 \%$ dos assinantes de TV por assinatura (TELA VIVA, 2013).

Tal fenômeno se deve ao fato de as operadoras de TV por assinatura, dispostas a não perderem clientes e com receio de que os assinantes não tenham condições de pagar por pacotes oficiais mais caros, 
abaixaram o preço de seus pacotes para atender a um novo mercado, das classes CDE (CANALTECH, 2014). De acordo com a Associação Brasileira de TV Paga (ABTA), com a crise atual brasileira, houve um crescimento no número de assinaturas dos receptores paralelos (piratas). Os receptores chamados de set top boxes abrem todos os canais da operadora sem o pagamento de mensalidades, permitindo acesso similar ao do assinante do pacote mais caro da operadora. Um estudo realizado pela ABTA em agosto de 2015 apontou que existem cerca de 5 milhões de assinaturas de TV pirata nas residências brasileiras (ZEAMERICA, 2015).

Já em relação ao consumo de música, percebeuse que pessoas com capital cultural mais elevado tendem a gostar mais de MPB, pop, rock e música clássica. Esse resultado confirma o estudo feito pelo Instituto Brasileiro de Opinião Pública e Estatística (2013) no que tange ao gosto dos indivíduos de maior renda pelos gêneros rock e MPB. Esse resultado também é corroborado por Ilari (2006), segundo o qual apreciadores de MPB tendem a serem pessoas politizadas e inteligentes e apreciadores de música clássica tendem a ser mais cultos. Coulangeon e Lemel (2007) também verificaram em seu estudo que os estilos mais eruditos tem correlação positiva com status, ao contrário dos estilos populares e considerados de "baixa cultura". Segundo esses autores, pessoas com alto nível educacional tendem a ouvir estilos mais eruditos, ao contrário dos que possuem níveis mais baixos. Diante desses resultados e, em consonância com Bourdieu (1984), pode-se dizer que o gosto por produtos culturais considerados legítimos (como a música clássica) está relacionado a uma sofisticação cognitiva que advém de um conjunto de qualificações que são restritas às classes mais altas.

Uma ressaltava interessante de ser feita diz respeito à diferença entre o status do gênero musical rock no Brasil em comparação com a Inglaterra. Conforme se observa no estudo desenvolvido por Bennett et al. (2009), o rock e heavy metal são associados aos estratos sociais mais baixos, ao passo que no
Brasil o rock é um gênero relacionado às classes sociais mais altas. Já o heavy metal (que pode ser considerado como um subgênero do rock), conforme será apresentado a seguir, se mostrou relacionado ao gosto dos indivíduos com capital cultural mais baixo. Assim, nota-se que fatores culturais locais também exercem influência sobre a estratificação do gosto musical, o que vai de encontro ao argumento de Rimmer (2011). Segundo esse autor, o campo da música precisa ser conceitualmente desagregado e percebido como composto por inúmeros subcampos, revelando a natureza complexa das correlações entre gosto-classe-capital.

Em relação ao consumo de música por parte dos indivíduos de capital cultural mais baixo, se destacam os gêneros gospel, sertanejo e heavy metal. A pesquisa Tribos Musicais, realizada pelo Instituto Brasileiro de Opinião Pública e Estatística (2013), também confirma esses resultados ao mencionar que os ouvintes de sertanejo são, em sua maioria, da classe $\mathrm{C}$, e os ouvintes de gospel da classe C, D e E. Corroborando, uma pesquisa feita pelo Instituto Futura, revelou que os consumidores evangélicos são simples e de baixa renda (SOUZA, 2015).

Nesse contexto, vale ressaltar o crescimento, a partir dos anos 1990, da população brasileira que se considera evangélica, passando de $9 \%$ em 1990 para 22,2\% em 2012 (IBGE, 2014). Esse crescimento pode ser explicado pelo aumento no número de igrejas autônomas, autóctones e a consolidação da Igreja Universal do Reino de Deus como uma igreja midiática (CUNHA, 2015).

O mercado evangélico no Brasil gira em torno de R $\$ 15$ bilhões por ano em diversos segmentos, sendo o principal responsável pela manutenção da indústria fonográfica no Brasil. Isso porque esse público tende a ser menos suscetível à pirataria e ao compartilhamento de áudios pela internet, o que iria de contra aos valores desses indivíduos. Por ano, o mercado de CD's e DVD's gospel movimenta cerca de R\$500 milhões (AMORIM; MARZANO; MANSUR, 2014). 
"Existem pelo menos 4,5 mil cantores e bandas gospel brasileiras. São, no mínimo, 10 novos CDs lançados todo mês. Especialistas em marketing que acompanham o fenômeno evangélico calculam que 600 rádios e 157 gravadoras tocam música gospel no país" (AMORIM; MARZANO; MANSUR, 2014, p. 1).

Lucas (2015) ainda acrescenta que ritmos musicais como rock, pop, dance, funk, hip-hop, pagode, axé, samba, forró, reggae e até música clássica (ainda que de forma minoritária), são normalmente encontrados nas produções evangélicas, o que também contribui com esse crescimento.

Um resultado curioso desse estudo diz respeito à maior propensão dos indivíduos de menor capital cultural a frequentar o cinema, shows e eventos musicais, o que contradiz o estudo do Instituto Brasileiro de Geografia e Estatística (2010), segundo o qual quanto maior a renda mensal familiar, maior é o gasto com cinema e shows.

Uma possível explicação para a baixa participação dos indivíduos de capital cultural mais elevado nos eventos de música, seria a prevalência de shows e eventos musicais de música sertaneja na cidade de Lavras, o que deixaria os indivíduos de classe social mais elevada (que tendem a não apreciar esse gênero musical) sem opções de participação. O estilo sertanejo se destaca na cultura musical da cidade de Lavras. Esse é o estilo mais tocado nas festas e bares locais, sendo o Rodeio Universitário, realizado anualmente, um dos eventos musicais mais importantes da cidade.

Já em relação à maior participação dos indivíduos de capital cultural mais baixo nos cinemas, o resultado pode ser explicado em virtude da veiculação de filmes populares no cinema da cidade de Lavras-MG, que raramente ou nunca exibe filmes relacionados à arte, que poderiam gerar um maior interesse nos indivíduos de maior capital cultural. Nesse sentido, o cinema em Lavras (e talvez de cidades de porte pequeno e médio) parece se configurar mais como uma forma de entretenimento do que de apreciação da arte. Esse pressuposto corrobora o estudo de Fleck e Casagrande (2006), que na tentativa de compreender a motivação das pessoas para frequentar o cinema, descobriram que o principal motivo não é causado por razões culturais, mas sim pela busca por entretenimento.

\section{Considerações Finais}

Esta pesquisa buscou identificar a influência do capital cultural no gosto e no consumo de TV, música e cinema. Os resultados obtidos evidenciam a influência do capital cultural no gosto e no consumo de TV, música e cinema por parte dos respondentes.

No campo cultural da música, o gosto musical dos indivíduos de capital cultural mais alto abrange os gêneros musicais considerados mais cultos e que tem relação com classes sociais mais elevadas, como o MPB e a música clássica. Já os indivíduos de capital cultural mais baixo preferem gêneros como o gospel, heavy metal e sertanejo, que são originalmente e culturalmente associados aos estratos sociais inferiores e, por conseguinte, apresentam menor prestígio e status.

Em relação ao campo cultural da televisão, observou-se que a elevação no capital cultural corresponde a uma maior posse de aparelhos eletrônicos, como TV plasma, LED ou LCD. Já a posse de TV por assinatura ou cabo e o tempo despendido no consumo de TV durante a semana e nos finais de semana se mostrou negativamente correlacionado ao capital cultural. Conforme discutido no presente estudo, esse resultado pode ser devido às medidas adotadas pelas companhias de TV por assinatura, frente ao crescimento do uso da internet e das assinaturas de receptores paralelos (piratas). Desta forma, para não perder público e audiência, as empresas de TV paga reduziram os preços para atingirem as classes CDE. Depreende-se, dessa forma, que a televisão ainda se constitui como um dos principais meios de lazer para as classes mais baixas.

Quanto ao campo cultural do cinema, os resultados revelaram que pessoas com menor capital cultural tenderem a ir com mais frequência 
ao cinema. Talvez, a exibição de filmes, majoritariamente de caráter popular nas salas de Lavras tenha interferido nesse resultado, uma vez que deixa de abarcar produções relacionadas ao cinema-arte e que poderiam despertar maior interesse dos indivíduos com capital cultural mais elevado. Esse é um resultado curioso desse estudo e que carece que novas investigações futuras para que os motivos sejam investigados em profundidade.

Diante desses resultados, pode-se dizer que o capital cultural exerce influência na diferenciação do gosto nos campos culturais da música, televisão e do cinema. Assume-se, portanto, que a consideração desse fator se faz relevante para o entendimento do consumo cultural nesses campos.

Destarte, pode-se dizer que esse artigo contribui com o campo das ciências humanas e sociais ao trazer para discussão um tema ainda pouco explorado, especialmente no contexto de países menos desenvolvidos. Ademais, a compreensão das diferenças no gosto por televisão e cinema entre os diferentes níveis de capital cultural pode auxiliar os agentes atuantes no mercado de música, televisão e cinema a planejar e definir de forma mais assertiva suas estratégias, de forma a atender melhor às necessidades e os desejos do seu público alvo, gerando valor perante seus consumidores.

Dentre as limitações desse estudo, ressalta-se o recorte geográfico, que impede a generalização dos resultados para o contexto brasileiro. Como o estudo aqui exposto foi realizado na cidade de Lavras, um município de médio porte e do interior do estado de Minas Gerais, existe probabilidade de os resultados apresentados não serem similares se o mesmo estudo for feito em outro local com características distintas. Sugere-se que estudos futuros busquem desenvolver investigações similares em outras regiões do país, de forma a permitir comparações entre os resultados e a identificar similaridades e peculiaridades do consumo nos campos da música, cinema e televisão no Brasil. Estudos qualitativos, que busquem investigar em profundidade essa temática, também poderiam contribuir com a compreensão e explicação da variabilidade no gosto musical brasileiro. Além disso, estudos transversais e o estudo do consumo em outros campos culturais, como da literatura, também se mostraram relevantes.

\section{Referências}

AMORIM, D.; MARZANO, F.; MANSUR, C. Mercado evangélico faz girar cerca de $R \$$ 15 bi por ano com vendas de CDs e vestuário. 2014. Disponível em: <http://www.em.com. br/app/noticia/economia/2014/01/30/internas economia,493161/mercado-evangelico-faz-girarcerca-de-r-15-bi-por-ano-com-vendas-de-cds-evestuario.shtml>. Acesso em: 12 out. 2015.

ANCINE. TV paga: mapeamento. 2010. Disponível em: <http://www.ancine.gov.br/media/SAM/Estudos/ Mapeamento_TvPaga_Publicacao.pdf $>$. Acesso em: 5 out. 2015.

ASSOCIAÇÃO BRASILEIRA DE TV POR ASSINATURA - ABTA. Evolução do número de assinantes de TV por assinatura. 2015. Disponível em: <http://www.abta.org.br/dados_do_setor.asp >. Acesso em: 12 out. 2015.

BAUER, C. Sobre a televisão: reflexões históricas. 2002. Disponível em: <http://www.spell.org.br/ documentos/download/23589>. Acesso em: 5 abr. 2015.

BENNETT, T. et al. Class, culture, distinction. London: Routledge, 2009.

BORLINA FILHO, V. Cidades de médio porte são as que mais crescem, aponta IBGE. 2012. Disponível em: $<\mathrm{http}$ ://agencia.ipea.gov.br/index.php?option $=\mathrm{com}$ content\&view $=$ article $\& i d=15352 \geq$. Acesso em: 5 mar. 2013.

BOURDIEU, P. Distinction. London: Routledge, 1984.

CANALTECH. Operadoras de TV a cabo devem lançar planos mais baratos para classes D e E. 2014. Disponível em: <http://canaltech.com.br/noticia/ mercado/Operadoras-de-TV-a-cabo-devem-lancarplanos-mais-baratos-para-classes-D-e-E/\#>. Acesso em: 5 out. 2015. 
CHAN, T. W.; GOLDTHORPE, J. H Social stratification and cultural consumption: music in england. European Sociological Review, Oxford, v. 23, n. 1, p. 1-19, 2006.

COULANGEON, P.; LEMEL, Y. Is 'distinction' really outdated? Questioning the meaning of the omnivorization of musical taste in contemporary France. Poetics, Amsterdam, v. 35, n. 2-3, p. 93-111, 2007.

CUNHA, M. N. Chaves teórico-interpretativas do processo de aproximação das Organizações Globo com o segmento evangélico no Brasil: audiência, mercado, política e poder. Comunicação \& Inovação, São Caetano do Sul, v. 16, n. 31, p. 59-75, maio/ago. 2015.

FELTRIN, R. Ibope de todas as TVs cresce em 2014, sóo da Globo cai. 2014. Disponível em: $<$ http://celebridades. uol.com.br/ooops/ultimas-noticias/2014/05/07/ibopede-todas-as-tvs-cresce-em-2014-so-o-da-globo-cai. htm>. Acesso em: 9 ago. 2015.

FLECK, J. P. S; CASAGRANDE, L. Consumo de cinema em Porto Alegre: motivações e atributos. In: ENCONTRO ANUAL DA ASSOCIAÇÃO NACIONAL DE PÓS-GRADUAÇÃO E PESQUISA EM ADMINISTRAÇÃO, 30., 2006, Salvador. Anais... Salvador: ANPAD, 2006.

FU, W. W. National audience tastes in Hollywood film genres: cultural distance and linguistic affinity. Communication Research, Beverly Hills, v. 20, n. 10, p. 1-29, 2013.

GAMBARO, D. Bourdieu, Baudrillard e Bauman: o consumo como estratégia de distinção. Revista Novos Olhares, São Paulo, v. 1, n. 1, p. 19-26, 2012.

GIL, A. C. Como elaborar projetos de pesquisa. 4. ed. São Paulo: Atlas, 2002.

HAMBURGER, E. Violência e pobreza no cinema brasileiro recente. Novos Estudos Cebrap, São Paulo, n. 78, pp. 113-128, jul. 2007.

HOLT, D. Does cultural capital structure American consumption? Journal of Consumer Research, Gainesville, v. 25, jun. 1998.
ILARI, B. Música, comportamento social e relações interpessoais. Psicologia em Estudo, Maringá, v. 11, n. 1, p. 191-198, 2006.

INSTITUTO BRASILEIRO DE GEOGRAFIA E ESTATÍSTICA - IBGE. Estimativas da população residente nos municipios brasileiros com data de referência em $1^{o}$ de julho de 2014. 2014. Disponível em: <ftp://ftp.ibge.gov.br/Estimativas de_Populacao/Estimativas_2014/ estimativa dou_2014.pdf>. Acesso em: 9 abr. 2015.

IBGE. Pesquisa de orçamentos familiares 20082009: despesas, rendimentos e condições de vida. Rio de Janeiro, 2010. Disponível em: <http:// biblioteca.ibge.gov.br/visualizacao/livros/liv45130. pdf $>$. Acesso em: 10 jul. 2015.

INSTITUTO BRASILEIRO DE OPINIÃO PÚBLICA E ESTATÍSTICA - IBOPE. Brasileiros passam mais tempo em frente à $T V$. 2014. Disponível em: $\quad<$ http://www.ibope.com.br/pt-br/noticias/ Paginas/Brasileiros-passam-mais-tempo-em-frentea-TV.aspx>. Acesso em: 5 jul. 2015.

- Tribos musicais. 2013. Disponível em: $\quad<$ http://www.ibope.com.br/pt-br/noticias/ Documents/tribos_musicais.pdf $>$. Acesso em: 11 jul. 2015.

LAMONT, M. Moneys, morals, and manners: the culture of the french and American uppermiddle class. Chicago: University of Chicago Press, 1992.

LUCAS, A. Análise do crescimento da música gospel brasileira. Disponível em: <http://artigos. gospelprime.com.br/analise-do-crescimento-damusica-gospel-brasileira/>. Acesso em: 3 out. 2015.

MATTOS, S. Um perfil da TV brasileira: 40 anos de história (1950 - 1990). Salvador: Associação Brasileira de Agências de Propaganda, 1990.

MELO, J. M. Comunicação, opinião e desenvolvimento. 3. ed. Petrópolis: Vozes, 1977.

MORETTIN, E. V. As exposições universais e o cinema: história e cultura. Revista Brasileira de História, São Paulo, v. 31, n. 61, 2011. 
PORTAL BRASIL. Cidadãos ganham linha de crédito para mobiliar suas casas. 2013. Disponível em: <http://www.brasil.gov.br/ infraestrutura/2013/06/copy_of_acompanhe-aovivo-lancamento-do-minha-casa-melhor $\geq$. Acesso em: 3 jul. 2015.

PORTAL METRÓPOLE. Globo perde patrocinadores com audiência despencando. 2015. Disponível em: <http://portalmetropole. com/2015/04/globo-perde-patrocinadores-com. html>. Acesso em: 5 ago. 2015.

RIMMER, M. Beyond omnivores and univores: the promise of a concept of musical habitus. Cultural Sociology, Thousand Oaks, v. 6, n. 3, p. 299-318, 2011.

SAVAGE, M.; GAYO, M. Unravelling the omnivore: a field analysis of contemporary musical taste in the United Kingdom. Poetics, Amsterdam, v. 39, n. 5, p. 337-357, 2011.

SIMMEL, G. Fashion. International Quarterly, Farmingdale, v. 10, 1904.

SOUZA, L. E. A fé alavanca as vendas. Disponível em: <http://revistapegn.globo.com/Empresasenego $\operatorname{cios} / 0,19125$, ERA455486 -2482,00.html $>$. Acesso em: 2 out. 2015.

TAMPUBOLON, G. Distinction in Britain, 20012004? unpacking homology and "aesthetics" of the popular class. European Societies, Rouen, v. 10, n. 3, p. 403-428, 2008.

TELA VIVA. 95\% de novos clientes de TV por assinatura são classe C ou D. Exame, São Paulo, abr. 2013. Disponível em: <http://exame.abril. com.br/tecnologia/noticias/95-de-novos-clientesde-tv-por-assinatura-sao-classe-c-ou-d $>$. Acesso em: 5 jul. 2015.

USTUNER, T.; HOLT, D. B. Toward a theory of status consumption in less industrialized countries. Journal of Consumer Research, Gainesville, v. 37, 2009.

VEBLEN, T. A teoria da classe ociosa: um estudo econômico das instituições. São Paulo: Abril, 1980.
WALTRICK, R. Pesquisa mostra aumento do uso de smartphones e tablets por jovens brasileiros. Gazeta do Povo, Curitiba, 13 out. 2014. Tecnologia. Disponível em: <http://www.gazetadopovo.com. $\mathrm{br} /$ tecnologia/pesquisa-mostra-aumento-do-usode-smartphones-e-tablets-por-jovens-brasileiroseevm0fcd3avhf5vxwpcmi6de6>. Acesso em: 2 jul. 2015.

ZEAMERICA. Aumento da pirataria da TV paga assusta operadoras. 2015. Disponível em: <http:// zeamerica.com.br/aumento-pirataria-tv-assustaoperadoras/>. Acesso em: 6 out. 2015. 
